\title{
Relationship between moisture content and electrical impedance of carrot slices during drying**
}

\author{
Ákos Kertész ${ }^{1}$, Zuzana Hlaváčová ${ }^{1 *}$, Eszter Vozáry ${ }^{2}$, and Lenka Staroňová ${ }^{3}$ \\ ${ }^{1}$ Department of Physics, Slovak University of Agriculture in Nitra, Tr. A Hlinku 2, SK-949 76 Nitra, Slovakia \\ ${ }^{2}$ Department of Physics and Control, Corvinus University of Budapest, Somlói út 14-16, H-1118 Budapest, Hungary \\ ${ }^{3}$ Department of Production Engineering, Slovak University of Agriculture in Nitra, Tr. A. Hlinku 2, SK-949 76 Nitra, Slovakia
}

Received September 2, 2014; accepted December 15, 2014

\begin{abstract}
A bstract. Electrical properties of food materials can give information about the inner structure and physiological state of biological tissues. Generally, the process of drying of fruits and vegetables is followed by weight loss. The aim of this study was to measure the impedance spectra of carrot slices during drying and to correlate impedance parameters to moisture content in different drying periods. Cylindrical slices were cut out from the carrot root along the axis. The slices were dried in a Venticell 111 air oven at $50^{\circ} \mathrm{C}$. The weight of the slices was measured with a Denver SI-603 electronic analytical and precision balance. The weighing of the samples was performed every $30 \mathrm{~min}$ at the beginning of drying and every $60 \mathrm{~min}$ after the process. The moisture content of the samples was calculated on wet basis. The magnitude and phase angle of electrical impedance of the slices were measured with HP 4284A and 4285A precision LCR meters in the frequency range from $30 \mathrm{~Hz}$ to $1 \mathrm{MHz}$ and from $75 \mathrm{kHz}$ to $30 \mathrm{MHz}$, respectively, at voltage $1 \mathrm{~V}$. The impedance measurement was performed after weighting. The change in the magnitude of impedance during drying showed a good correlation with the change in the moisture content.

K e y w or d s: carrot slice, drying, moisture content, electrical impedance spectroscopy, LCR meter
\end{abstract}

\section{INTRODUCTION}

Electrical properties of biological materials can give information about the inner structure and physiological state of biological tissues. The requirements of the user industry in terms of the quality of purchased vegetables are growing. In addition, vegetables must meet national quality standards and obviously the rules of the European Union. Therefore, we need to constantly monitor and control their quality from producer to consumer. Alternatively, the pos-

*Corresponding author e-mail: zuzana.hlavacova@uniag.sk

**This work was co-funded by the European Community under the project No 26220220180: Building the Research Centre AgroBioTech., 2013-2015. sibility of carrot preservation can be enhanced by drying and subsequent storage. Drying operations are important steps in the food processing industry. Drying is one of the oldest methods of food preservation, and it represents a very important aspect of food processing. In this case, we need knowledge about thermophysical properties of materials (Božiková and Hlaváč, 2013; Vozárová et al., 2011).

When studying the physical properties of tissue, it is necessary to consider its non-homogeneity from the macroscopic and microscopic points of view. When testing the electrical properties from the microscopic point of view, it is apparent that the interior of the cell is conductive because there is conductivity of ion type in the content of the organic and inorganic matter solutions. Cell membranes are not conductors. From the macroscopic point of view, it is possible to regard biological materials as non-homogeneous semi-conductors or dielectrics. The density and structural arrangement of the cells therein and the properties of each type of tissue influence the electrical properties of these materials. For porous materials, the following can be regarded as influential factors: the size and distribution of pores, porosity, and bulk density. Other factors are the temperature of the material, but the most significant is the influence of the presence of water, its uneven deployment in the material, different binding energy in each water bond in the material, and sorption properties (Hlaváčová, 2003). The electric properties of biological materials can be measured by various methods and can be utilized in a wide range of disciplines and industries (Jha et al., 2011; Kovalyshyn et al., 2013; Miclaus and Morega, 2010; Paszkowski et al., 2014; Venkatesh and Raghavan, 2005).

(C) 2015 Institute of Agrophysics, Polish Academy of Sciences 
In plant materials, dielectric measurements have been used for determining mechanical damage and biological changes in fruit or vegetable tissues. The results of these measurements may also be used for evaluating the quality and physical state of fruit during ripening and storage (Bauchot et al., 2000; Harker and Maindonald, 1994).

Frequency, temperature, salt content, moisture content, and the state of moisture (frozen, free or bound) are the major factors that influence dielectric properties of agricultural and biological materials. Many studies on dielectric properties of vegetables and fruits have been reported for different frequency ranges, temperatures, and moisture contents (Garcia and Barret, 2002; Nelson, 2005).

Some authors studied also the dielectric properties of vegetable and fruit flour in relation to dielectric heating (Guo et al., 2010). Sosa-Morales et al. (2010) described dielectric properties of foodstuff, which have gained great importance and applications for food that are subjected to microwave or radio frequency (RF) heating treatments. Alfaifi et al. (2013), Marra et al. (2009), and Wang et al. (2010) described the use of RF treatments also at post-harvest disinfestations and insect control in fruits and vegetables.

The instantaneous controlled pressure drop treatment is used for creation of a porous structure during the drying of fruits and vegetables. This treatment is based on high-temperature short-time heating followed by an abrupt pressure drop into a vacuum. Treated products exhibited slightly lower dielectric properties than raw products (Kristiawan et al., 2011). Information on the dielectric properties of commodities and insect pests is needed in developing thermal treatments for post-harvest insect control based on radio frequency and microwave energy.

Many authors use mathematical models for describing the drying process. The effects of air temperature, air-flow rate, and sample thickness on the kinetics of drying of carrot cubes were investigated by Doymaz (2004). The Page model gave better prediction than the Henderson and Pabis model and satisfactorily described the drying characteristics of carrot cubes. The drying of Maitake mushroom (Grifola frondosa), which has a high initial moisture content, was analyzed by Cao et al. (2003), who used the modified plate drying model. Results indicated that the model fitted reasonably well with experimental results for different drying conditions. To simulate the dynamics of soya bean thinlayer drying, a two-layer grain model has been proposed by Khatchatourian (2012). The model consists of two ordinary differential equations and includes the influence of all studied parameters. The study of Birla et al. (2008) showed that dissimilarity in the peel and pulp dielectric properties greatly influenced the RF heating behaviour of fruits. They used a computer model, which was an effective tool in characterizing and explaining the heating patterns in fruits based on dielectric properties.

The experimental results of the moisture content of material undergoing microwave drying were in good agreement with the moisture content of a sample predicted by the coupled mathematical model (Hemis et al., 2012). The three numerical methods used in the mathematical model for low-temperature natural-air drying allow the system of drying equations to be solved by Martinello et al. (2013). The comparison of models and methods for simulating the microwave heating of moist foodstuffs was described by Budd and Hill (2011).

The aim of this study was to determine the relationship between the impedance parameters and moisture content and moisture ratio of carrot slices during drying.

\section{MATERIAL AND METHODS}

Our experiments were done on carrots (Daucus carota L.) from a local market. The samples were stored in an open polyethylene bag in a refrigerator at $5-7^{\circ} \mathrm{C}$. The samples were stored for a shorter period ( $c a$. a day), or a longer period ( $c a$. a week). At the beginning of each experiment, the carrots were washed and cut into cylindrical slices, which consisted of both the orange exterior and the yellow core, having variable dimensions, using a kitchen shear.

The carrot slices were dried in a Venticell 111 dryer at $50^{\circ} \mathrm{C}$ installed at the Department of Physics and Control, Corvinus University of Budapest. Since biological materials can absorb humidity from the air, the samples were wrapped immediately after drying in a thin film to stabilize its moisture. Just before the measurement, the thin film was removed and the samples were weighted. The initial moisture content (wet basis) of carrots was about $87.5 \%$ (AOAC, 1990). The weight of the slices was measured with a Denver SI-603 electronic analytical and precision balance. The weighing of the samples was performed every $30 \mathrm{~min}$ at the beginning of drying $(30,60,90 \mathrm{~min})$ and afterwards every $60 \mathrm{~min}$ till $990 \mathrm{~min}$. The moisture content of the samples was calculated on wet basis. The magnitude and phase angle of electrical impedance of the slices were measured with HP 4284A and 4285A precision LCR meters in the frequency range from 30 to $1 \mathrm{MHz}$ and from 75 to $30 \mathrm{MHz}$, respectively, at voltage $1 \mathrm{~V}$. A special electrode with clips hp16451 B dielectric test fixture, intended for the LCR meters hp4284A and hp4285A for measuring dielectric properties of materials, was used as a sensor. The dried slices of carrots were located between two plates of the dielectric test fixture. The impedance measurement was executed after weighing.

\section{RESULTS AND DISCUSSION}

In most studies carried out with drying, diffusion is generally accepted to be the main mechanism during the transport of moisture to the surface to be evaporated. Moisture ratio is defined as:

$$
M_{R}=\frac{u-u_{e}}{u_{0}-u_{e}},
$$

where: $M_{R}$ is moisture ratio, $u, u_{0}$, and $u_{e}$ are local, initial, and equilibrium moisture contents, respectively. 
The solution of Fick equation, with the assumptions of moisture migration being by diffusion, negligible shrinkage, constant diffusion coefficients, and temperature, and for a sphere:

$$
M_{R}=\frac{6}{\pi^{2}} \sum_{n=1}^{\infty} \frac{1}{n^{2}} \exp \left(-\frac{\pi^{2} n^{2} D_{e f f} t}{r^{2}}\right) .
$$

where: $r$ is radius (m), $t$ is time (s), and $D_{\text {eff }}$ is effective diffusivity $\left(\mathrm{m}^{2} \mathrm{~s}^{-1}\right)$.

The model of Henderson and Pabis is the first term of general series solution of Fick second law. Moisture ratio:

$$
M_{R}=\frac{u-u_{e}}{u_{0}-u_{e}}=\frac{6}{\pi^{2}} \exp \left(-\frac{\pi^{2} D_{e f f} t}{r^{2}}\right) .
$$

Equation (3) can also be written in a more simplified form as:

$$
M_{R}=\mathrm{k} \exp (-\mathrm{c} t)
$$

where: $\mathrm{c}$ is constant $\left(\mathrm{s}^{-1}\right), \mathrm{k}$ is constant $(-)$.

Another widely applied empirical equation is the Page equation. The Page model has been widely advocated for thin-layer drying of solids under constant drying conditions. This model has produced good fits in predicting the drying of sweet potato, garlic, apricot, seedless grapes, and mint leaves (Doymaz, 2004; Sharma and Prasad, 2002). It is written in the following form:

$$
M_{R}=\frac{u-u_{e}}{u_{0}-u_{e}}=\exp \left(-\mathrm{z} t^{\mathrm{N}}\right)
$$

where: $\mathrm{z}$ is constant $\left(\mathrm{s}^{-\mathrm{N}}\right)$ and $\mathrm{N}$ is constant $(-)$.

The values of the equilibrium moisture content, $u_{e}$, are relatively low compared to $u$ or $u_{0}$. Thus $\left(u-u_{e}\right) /\left(u_{0}-u_{e}\right)$ is simplified to $u / u_{0}$ (Doymaz, 2004):

$$
\begin{aligned}
& M_{R}=\frac{u}{u_{0}}=\mathrm{k} \exp (-\mathrm{c} t), \\
& M_{R}=\frac{u}{u_{0}}=\exp \left(-\mathrm{z} t^{\mathrm{N}}\right) .
\end{aligned}
$$

No constant rate-drying period was observed in any of the experiments of this study. The time of drying (from 0 to $990 \mathrm{~min}$ ), weight of samples (Nos 1, 3, 5), and moisture ratio are given in Table 1 . The moisture ratio versus time of drying curves for the samples Nos 2, and 5 as influenced by temperature $50^{\circ} \mathrm{C}$ are shown in Fig. 1. The effect of air temperature is reflected in the drying rate. At a temperature higher than $70^{\circ} \mathrm{C}$, the dried product partially

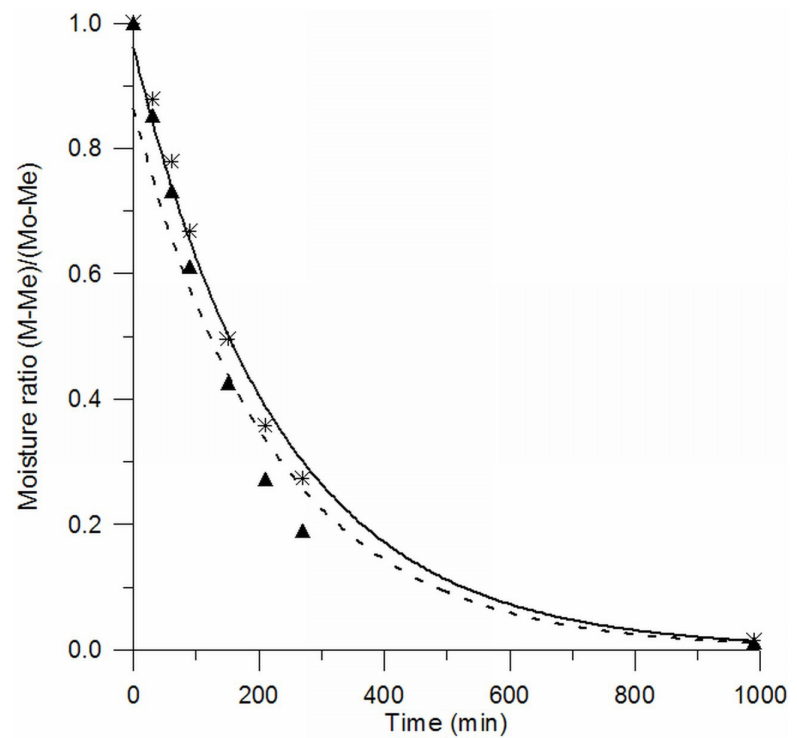

Fig. 1. Drying time dependence of the moisture ratio for carrot slices Nos $2-\triangle, 5-*$.

T a b l e 1. Drying time, weight, and moisture ratio of samples Nos 1,3 , and 5 during drying at $50^{\circ} \mathrm{C}$

\begin{tabular}{ccccccc}
\hline Sample & \multicolumn{3}{r}{ Slice 1 } & \multicolumn{2}{c}{ Slice 3 } & \multicolumn{2}{c}{ Slice 5 } \\
\hline Drying time (min) & $\begin{array}{c}\text { Mass } \\
(\mathrm{g})\end{array}$ & $M_{R}$ & $\begin{array}{c}\text { Mass } \\
(\mathrm{g})\end{array}$ & $M_{R}$ & $\begin{array}{c}\text { Mass } \\
(\mathrm{g})\end{array}$ & $M_{R}$ \\
\hline 0 & 7.888 & 1 & 8.195 & 1 & 7.985 & 1 \\
30 & 7.019 & 0.878 & 7.266 & 0.874 & 7.115 & 0.879 \\
60 & 6.305 & 0.778 & 6.481 & 0.768 & 6.392 & 0.779 \\
90 & 5.600 & 0.679 & 5.712 & 0.665 & 5.589 & 0.668 \\
150 & 4.423 & 0.514 & 4.453 & 0.495 & 4.350 & 0.496 \\
210 & 3.460 & 0.379 & 3.399 & 0.353 & 3.347 & 0.358 \\
270 & 2.871 & 0.297 & 2.802 & 0.272 & 2.742 & 0.274 \\
990 & 0.821 & 0.010 & 0.865 & 0.011 & 0.861 & 0.014 \\
\hline
\end{tabular}


lost its fresh product characteristics (Mulet et al., 1987). The moisture ratio decreased with the drying time, and after drying, the moisture content (w.b.) ranged from $c a .7$ to $8 \%$. As we can see, the change in the moisture ratio at the beginning of the drying period is significant, compared to the final stage of drying where very small changes in the moisture ratio were reported. These illustrated curves can be approximated by an exponential function:

$$
M_{R}=M_{R 0} e^{-\mathrm{c} t}
$$

where $M_{R 0}$ is a reference value of the moisture ratio (-).

The coefficients of regression equation Eq. (8) and the coefficient of determination are presented in Table 2. The values of the coefficient of determination range from 0.9865 to 0.9983 . Our measurement confirmed the reliability of Eq. (6) for thin slices of carrot.

The moisture content $\omega$ versus time curves for the thin layers of carrots Nos 1, 2, 3, and 6 are shown in Fig. 2. These curves can be approximated with a polynomial (quadratic) function:

$$
\omega=\mathrm{a} t^{2}+\mathrm{b} t+\omega_{0}
$$

where: $\mathrm{a}$ is constant $\left(\mathrm{s}^{-2}\right), \mathrm{b}$ is constant $\left(\mathrm{s}^{-1}\right)$, and $\omega_{0}$ is the reference value of the moisture content.

Comparing the curve shapes in Fig. 2, it can be seen that the curves have a similar time behaviour, and it is evident that during drying the moisture content of the samples decreases. The coefficients of regression equation Eq. (9) and coefficient of determination are mentioned in Table 3. The coefficient of determination has high values, ie from 0.9986 to 0.9992 .

Figure 3 illustrates the frequency dependence of impedance for the samples of carrot slices Nos 21,24, and 25. The samples were measured after different drying time; sample Nos 21, 24, and 25 was dried for 570, 630, and $1440 \mathrm{~min}$, respectively. The following charts are shown by the power function:

$$
Z=Z_{o}\left(\frac{f}{f_{o}}\right)^{x}
$$

where: $Z$ is impedance $(\Omega), Z_{o}$ is the reference value of impedance $(\Omega), f$ is frequency $(\mathrm{Hz}), f_{o}=1 \mathrm{~Hz}$, and $\mathrm{x}$ is constant (-).

T a b l e 2. Coefficient of regression equation Eq. (8) and coefficients of determination

\begin{tabular}{cccc}
\hline Slice & $M_{R 0}$ & $\mathrm{c}\left(\mathrm{s}^{-1}\right)$ & $\mathrm{R}^{2}$ \\
\hline 2 & 0.8637 & -0.0045 & 0.9865 \\
5 & 0.9611 & -0.0043 & 0.9983 \\
\hline
\end{tabular}

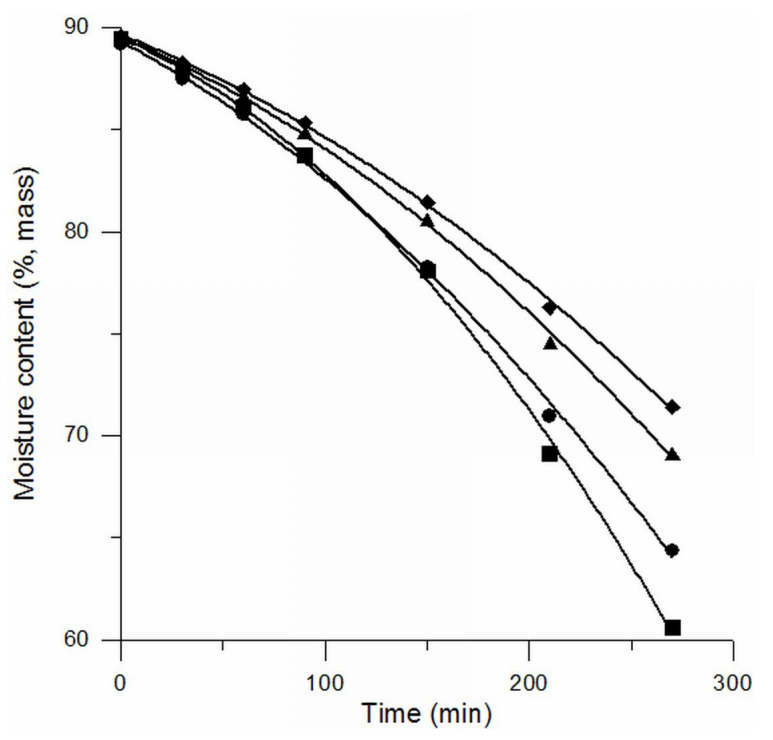

Fig. 2. Drying time dependence of the moisture content (w. b.) for samples Nos: $1-\bullet, 2-\mathbf{m}, 3-\boldsymbol{\Lambda}, 6-\bullet$.

T a b l e 3. Coefficient of regression equation Eq. (9) and coefficients of determination

\begin{tabular}{ccccc}
\hline Slice & $\mathrm{a}\left(\mathrm{s}^{-2}\right)$ & $\mathrm{b}\left(\mathrm{s}^{-1}\right)$ & $\omega_{0}(\%)$ & $\mathrm{R}^{2}$ \\
\hline 1 & -0.0001 & -0.0398 & 89.654 & 0.9992 \\
2 & -0.0002 & -0.0429 & 89.486 & 0.9988 \\
3 & -0.0001 & -0.0419 & 89.530 & 0.9988 \\
6 & -0.0002 & -0.0516 & 89.300 & 0.9986 \\
\hline
\end{tabular}

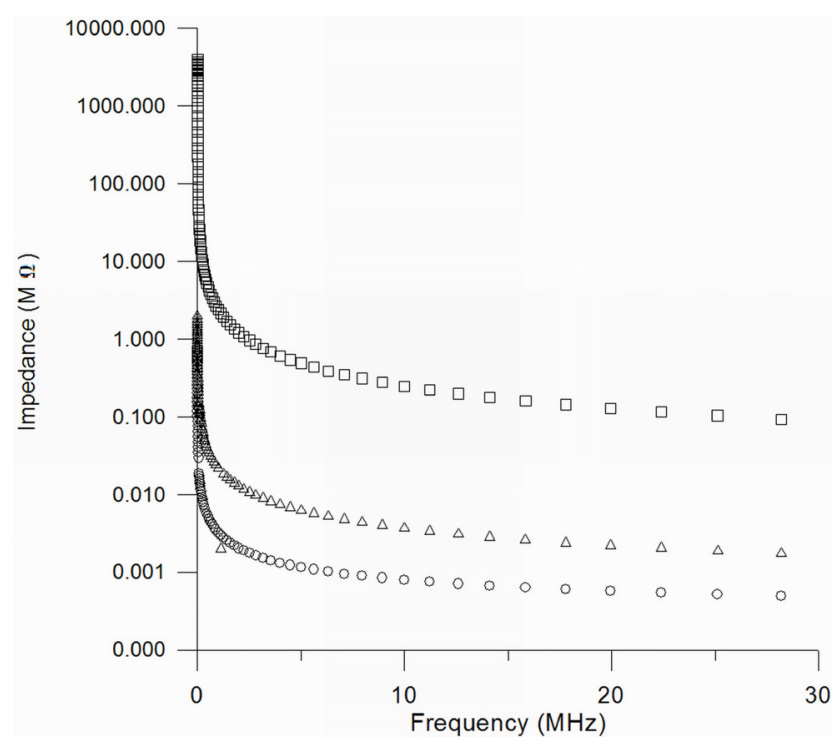

Fig. 3. Frequency dependence of impedance for slices Nos $21-0$ $570 \mathrm{~min}, 24-\triangle 630 \mathrm{~min}, 25-\square 1440 \mathrm{~min}$. 
T a b l e 4. Coefficient of regression equation Eq. (10) and coefficients of determination for samples Nos 21, 24, and 25

\begin{tabular}{lccc}
\hline Sample & $Z_{0}(\mathrm{M} \Omega)$ & $\mathrm{x}$ & $\mathrm{R}^{2}$ \\
\hline Slice 21-570 min & 20 & -0.6104 & 0.9820 \\
Slice 24-630 min & 30 & -0.5154 & 0.9621 \\
Slice 25-1440 min & 400000 & -0.8617 & 0.9706 \\
\hline
\end{tabular}

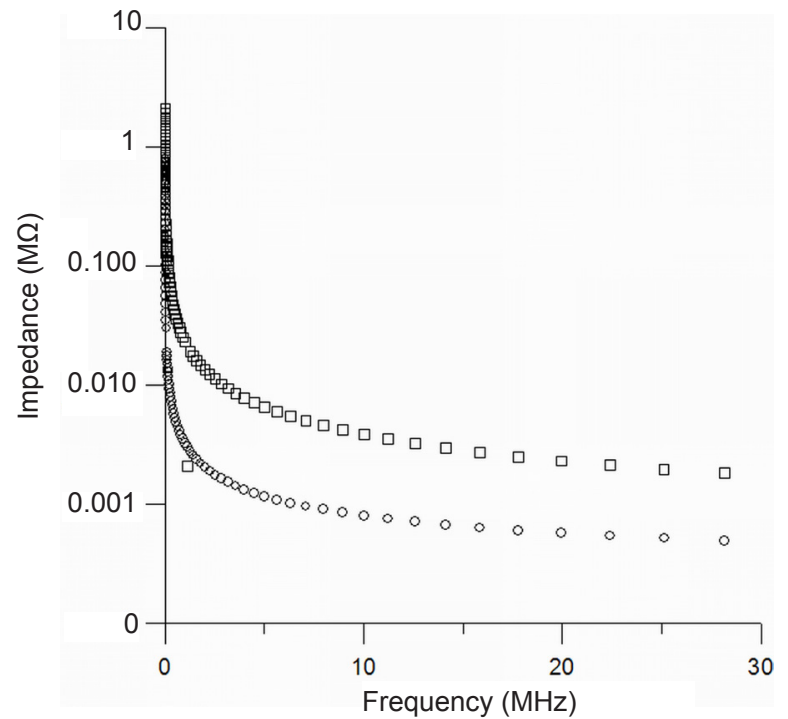

Fig. 4. Frequency dependence of impedance for carrot slice No. $16 \circ-660 \mathrm{~min}, \square-780 \mathrm{~min}$.

T a b l e 5. Coefficient of regression equation Eq. (10) and coefficients of determination for sample No. 16

\begin{tabular}{lccc}
\hline Sample & $Z_{0}(\mathrm{M} \Omega)$ & $\mathrm{x}$ & $\mathrm{R}^{2}$ \\
\hline Slice 16-660 min & 300000 & -0.926 & 0.9931 \\
Slice 16-780 min & 200000 & -0.9056 & 0.9893 \\
\hline
\end{tabular}

Impedance depending on the frequency has a down ward tendency. The same dependence was found by Jha et al., (2011), and Vozáry and Kertész (2011). Table 4 contains the coefficients of regression equation Eq. (10) and coefficients of determination for the aforementioned samples. The coefficients of determination have high values. The displacement of the curves in Fig. 3 confirms that after alonger time of drying the moisture content is lower and the frequency dependence of sample impedance is situated higher on the chart.

Figure 4 illustrates the frequency dependence of impedance for the sample of dried carrot slice No. 16 after drying for 660 and $780 \mathrm{~min}$. The following charts are described by the power function Eq. (10). The impedance of samples with the same dimensions is increasing with the drying time because the moisture content of the samples also decreases with the drying time. In the final stage of drying, we recorded a very slight change in the values of the moisture content of the samples. The impedance of these samples at this stage does not differ greatly from each other, as shown in Fig. 4. Table 5 contains the coefficients of regression equation Eq. (10) and coefficients of determination.

\section{CONCLUSIONS}

Study of the most important characteristics (moisture content and moisture ratio) of carrot required for simulation and optimization of the drying process showed that:

1. The moisture ratio of the samples decreases with time.

2. Time dependence of the moisture ratio is valid for thin slices of carrot.

3. During drying, the moisture content of the samples decreases according to the polynomial (quadratic) function.

4. The impedance of the measured samples decreases in this frequency range according to the power function.

5. The impedance of carrot samples at the end of the drying process reached higher values in comparison with the beginning of drying when the samples had higher moisture content.

6. The coefficients of determination of all regression equations reached high values for all measured quantities and samples.

7. The change of impedance in drying time showed correlation with the change in the moisture content.

\section{REFERENCES}

Alfaifi B., Wang S., Tang J., Rasco B., Sablani S., and Jiao Y., 2013. Radio frequency disinfestation treatments for dried fruit: Dielectric properties. LWT - Food Sci. Technol., 50(2), 746-754.

AOAC, 1990. Official Method of Analysis. Association of Official Analytical Chemists (AOAC), Washington, DC, USA.

Bauchot A.D., Harker F.R., and Arnold A.M., 2000. The using of electrical impedance spectroscopy to assess the physiological condition of kiwifruit. Postharvest Biol. Technol., 18, 9-18.

Birla S.L., Wang S., Tang J., and Tiwari G., 2008. Characterization of radio frequency heating of fresh fruits influenced by dielectric properties. J. Food Eng., 89, 4, 390-398.

Božiková M. and Hlaváč P., 2013. Thermophysical measurement methods and their usage for detection of selected food materials thermophysical parameters, Proc. 5th Int. Conf. TAE, September 3-6, Prague, Czech Republic.

Budd C.J. and Hill A.D.C., 2011. A comparison of models and methods for simulating the microwave heating of moist foodstuffs. Int. J. Heat and Mass Transfer, 54(4), 807-817.

Cao W., Nishiyama Y., and Koide S., 2003. Thin-layer drying of Maitake mushroom analysed with a simplified model. Biosystems Eng., 85(3), 331-337.

Doymaz I., 2004. Convective air-drying characteristics of thin layer carrots. J. Food Eng., 61, 359-364. 
Garcia E.L. and Barret D.M., 2002. Preservative treatments for fresh-cut fruits and vegetables. In: Fresh-cut fruits and vegetable. Science, Technology and Market (Ed. O. Lamikanra). CRC Press, Boca Raton, FL, USA.

Guo W., Wang S., Tiwari G., Johnson J.A., and Tang J., 2010. Temperature and moisture dependent dielectric properties of legume flour associated with dielectric heating. LWT Food Sci. Technol., 43(2), 193-201.

Harker F.R. and Maindonald J.H., 1994. Ripening of nectarine fruit: changes in the cell wall, vacuole and membranes detected using electrical impedance measurement. Plant Physiol., 106, 165-171.

Hemis M., Choudhary R., and Watson D.G., 2012. A coupled mathematical model for simultaneous microwave and convective drying of wheat seeds. Biosys. Eng., 112, 202-209.

Hlaváčová Z., 2003. Low frequency electric properties utilization in agriculture and food treatment. Res. Agr. Eng., 49(4), 125-136.

Jha S.N., Narsaiah K., Basediya A.L., Sharma R., Jaiswal P., Kumar R., and Bhardwaj R., 2011. Measurement techniques and application of electrical properties for nondestructive quality evaluation of foods - a review. J. Food Sci. Technol., 48(4), 387-411.

Khatchatourian O.A., 2012. Experimental study and mathematical model for soya bean drying in thin layer. Biosys. Eng., 113, 54-64.

Kovalyshyn J., Shvets O.P., Grundas S., and Tys J., 2013. Use of the electro-separation method for improvement of the utility value of winter rapeseeds. Int. Agrophys., 27, 419-424.

Kristiawan M., Sobolik V., Klíma L., and Allaf K., 2011. Effect of expansion by instantaneous controlled pressure drop on dielectric properties of fruits and vegetables. J. Food Eng., 102(4), 361-368.

Marra F., Zhang L., and Lyng J.G., 2009. Radio frequency treatment of foods: Review of recent advances. J. Food Eng., 91(4), 497-508.
Martinello M.A., Muñoz D.J, and Giner S.A., 2013. Mathematical modelling of low temperature drying of maize: Comparison of numerical methods for solving the differential equations. Biosys. Eng., 114, 187-194.

Miclaus S. and Morega M., 2010. Characterisation of the electromagnetic environment in a TEM cell for exposure of small biological samples in the UHF band. Romanian J. Physics, 55(1-2), 195-204.

Mulet A., Berna A., Borras M., and Pinaga F., 1987. Effect of air flow rate on carrot drying. Drying Technol., 5(2), $245-258$

Nelson S.O., 2005. Dielectric spectroscopy in agriculture. J. NonCrystalline Solids, 351(33-36), 2940-2944.

Paszkowski B., Wilczek A., Szypłowska A., Nakonieczna A., and Skierucha W., 2014. A low-frequency sensor for determination of honey electrical properties in varying temperature conditions. J. Food Eng., 138, 17-22.

Sharma G.P. and Prasad S., 2002. Dielectric properties of garlic (Allium sativum L.) at $2450 \mathrm{MHz}$ as function of temperature and moisture content. J. Food Eng., 52(4), 343-348.

Sosa-Morales M.E., Valerio-Junco L., López-Malo A., and García H.S., 2010. Dielectric properties of foods: Reported data in the 21 st century and their potential applications. LWT - Food Sci. Technol., 43(8), 1169-1179.

Venkatesh M.S. and Raghavan G.S.V., 2005. An overview of dielectric properties measuring techniques. Canadian Biosys. Eng., 47, 7.15-7.30.

Vozárová V., Hlaváčová Z., and Tkáč Z., 2011. Methods for moisture content, electrical properties and thermal behaviour of food materials investigation. Scientific Monograph Modern Methods of Agricultural Raw Materials Analysis (Eds G. Bartosz, C. Puchalski), Rzeszów, University of Rzeszów, Poland.

Vozáry E. and Kertész Á., 2011. Impedance parameters of carrot slices during drying. Proc. 9th Int. Conf. Electromagnetic Wave Interaction with Water and Moist Substances ISEMA, May 31 - June 3, Kansas City, MI, USA.

Wang S., Tiwari G., Jiao S., Johnson J.A., and Tang J., 2010. Developing postharvest disinfestation treatments for legumes using radio frequency energy. Biosys. Eng., 105, 341-349. 